\title{
HUBUNGAN KUALITAS TIDUR DENGAN TINGKAT KECEMASAN MAHASISWA DALAM MENGHADAPI UJIAN CBT PADA MAHASISWA BARU DI FAKULTAS KEDOKTERAN UMUM UNIVERSITAS MALAHAYATI TAHUN 2019
}

\author{
Sri Maria Puji Lestari ${ }^{1}$, Esteria Marhayuni ${ }^{2}$,Octa Reni Setiawati ${ }^{3}$, Muhammad Nizar \\ Nugraha Kamil ${ }^{4}$ \\ ${ }^{1}$ Departemen IImu Kesehatan, Fakultas Kedokteran Universitas Malahayati \\ ${ }^{2}$ Departemen Ilmu Kesehatan, Fakultas Kedokteran Universitas Malahayati \\ ${ }^{3}$ Departemen Psikologi, Fakultas Psikologi Universitas Malahayati \\ ${ }^{4}$ Program Studi Kedokteran, Fakultas Kedokteran Universitas Malahayati
}

\begin{abstract}
Relationship Sleep Quality With Student Anxiety Levels In Facing CBT Exams In New Students In Faculty Of Medicine Malahayati University Of 2019. Sleep quality is one's satisfaction with sleep so that a person does not show feelings of fatigue, irritability, lethargy and apathy, blackness around the eyes, swollen eyelids, red conjunctiva, sore eyes, fragmented attention, fragmented attention, headaches, and frequent yawning or sleepy. Student anxiety can be influenced by many factors, one of which is sleep quality. Determine the relationship of sleep quality with the level of difficulty of students in the CBT exam for new students in the medical faculty of Malahayati University in 2019. This research is quantitative with analytical research methods and cross-sectional design, the population is new students. The 106 respondents studied were obtained frequency distribution of sleep quality shows that the majority of students have poor sleep quality of 76 people $(71.7 \%)$. The frequency distribution of anxiety shows that 28 students $(26.4 \%)$ had no anxiety. It is known that there is a relationship between sleep quality and the level of student anxiety in facing the CBT exam for new students in the faculty of general medicine at Malahayati University in 2019 with a $\mathrm{p}$-value $=0.033$.
\end{abstract}

Keywords: Sleep Quality, Anxiety, CBT

\begin{abstract}
Abstrak : Hubungan Kualitas Tidur Dengan Tingkat Kecemasan Mahasiswa Dalam Menghadapi Ujian CBT Pada Mahasiswa Baru Di Fakultas Kedokteran Umum Universitas Malahayati Tahun 2019. Kualitas tidur adalah kepuasan seseorang terhadap tidur, sehingga seseorang tidak memperlihatkan perasaan lelah, mudah gelisah, lesu dan apatis, kehitaman di sekitar mata, kelopak mata bengkak, konjungtiva merah, mata perih, perhatian terpecah-pecah, sakit kepala dan sering menguap atau mengantuk. Kecemasan mahasiswa dapat dipengaruhi dari banyak faktor, salah satunya adalah kualitas tidur. Mengetahui hubungan kualitas tidur dengan tingkat kecemasan mahasiswa dalam menghadapi ujian CBT pada mahasiswa baru. Penelitian kuantitatif dengan metode analitik dan desain cross sectional, populasi adalah Mahasiswa baru fakultas kedokteran umum Universitas Malahayati tahun 2019. Dari 106 responden yang diteliti didapatkan distribusi frekuensi kualitas tidur buruk sebanyak 76 orang $(71,7 \%)$. Distribusi frekuensi kecemasan terlihat bahwa mahasiswa yang tidak ada kecemasan sebanyak 28 orang $(26,4 \%)$. Ada hubungan kualitas tidur dengan tingkat kecemasan mahasiswa dalam menghadapi ujian CBT pada mahasiswa baru di fakultas kedokteran umum Universitas Malahayati tahun 2019 dengan nilai $p$-value $=0,033$.
\end{abstract}

Kata Kunci : Kualitas Tidur, Kecemasan, CBT 


\section{PENDAHULUAN}

Fakultas kedokteran umum merupakan salah satu fakultas yang memiliki jumlah mahasiswa terbanyak dari beberapa fakultas yang berada di Universitas Malahayati. Pada setiap akhir mata kuliah (Blok) akan dilaksanakan ujian yang dikenal dengan ujian blok. Ujian blok dilakukan dengan sistem CBT (Computer Based Test) yang mana mahasiswa melakukan ujian dengan mengisi soal yang tertera di dalam komputer sesuai waktu yang telah ditentukan, sehingga pada dasarnya pada mahasiswa baru ujian CBT membutuhkan proses adaptasi dari peralihan dari system ujian PBT (Paper Based Test) pada saat masih menjadi siswa SMA (Siswa Menengah Atas). Ujian blok juga merupakan salah satu stressor yang sering dialami oleh mahasiswa kedokteran (Kesuma, 2017).

Ujian merupakan suatu bagian dari persoalan yang dialami setiap peserta didik yang di dalamnya terdiri dari pertanyaan-pertanyaan dan latihan untuk menentukan, tingkat pengetahuan, kemampuan dan bakat atau kualifikasi peserta didik. Contohnya yaitu mahasiswa kedokteran sebagai peserta didik yang juga tidak terlepas dari ujian, salah satu hal yang dapat mempengaruhi performa mahasiswa kedokteran dalam menghadapi ujian adalah kecemasan (Amir et al, 2016).

Kecemasan dapat dikatakan sebagai sinyal terhadap ego bahwa adanya suatu dorongan yang menekan untuk mendapatkan perwakilan dan pelepasan sadar. Sebagai suatu sinyal, kecemasan menyadarkan ego untuk mengambil tindakan defensif terhadap adanya tekanan dari dalam. Selain itu, kecemasan merupakan keadaan emosional yang ditandai oleh rasa kekhawatiran atau ketakutan yang berasal dari pikiran atau harapan (Kaplan dan Sadock, 2010).

Kecemasan mahasiswa dapat dipengaruhi dari banyak faktor, salah satunya adalah kualitas tidur. Kondisi yang menyebabkan gangguan tidur pada mahasiswa adalah kondisi lingkungan kamar, sehingga kondisi ini dapat mempengaruhi kualitas tidur. Dalam kondisi kualitas tidur yang buruk, mahasiswa dapat mengalami perubahan emosi meliputi kecemasan, rasa takut dan depresi (Setyawan, 2017).

Kualitas tidur meliputi aspek kuantitatif dan kualitatif tidur, seperti lamanya tidur, waktu yang diperlukan untuk bisa tertidur, frekuensi terbangun dan aspek subjektif seperti kedalaman dan kepulasan tidur (Nilifda et al, 2016).Kualitas tidur adalah kepuasan seseorang terhadap tidur, sehingga seseorang tidak memperlihatkan perasaan lelah, mudah gelisah, lesu dan apatis, kehitaman di sekitar mata, kelopak mata bengkak, konjungtiva merah, mata perih, perhatian terpecah-pecah, sakit kepala dan sering menguap atau mengantuk (Hidayat, 2009).

Berdasarkan penelitian tentang kualitas tidur yang dilakukan oleh Setyawan pada tahun 2017 diperoleh hasil bahwa dari 20 orang $(37,7 \%)$ yang tidak cemas memiliki kualitas tidur yang baik sebanyak 18 orang $(34,0 \%)$ dan kualitas tidur tidak baik sebanyak 2 orang $(3,7 \%)$. Dari 10 orang $(18,9 \%)$ yang cemas ringan keseluruhan memiliki kualitas tidur tidak baik, begitu pula 19 orang $(35,8 \%)$ yang cemas sedang keseluruhan memiliki kualitas tidur tidak baik. Sebanyak 4 orang $(7,5 \%)$ cemas berat keseluruhan memiliki kualitas tidur yang buruk juga.

Kecemasan mempengaruhi organ viseral dan motorik, pikiran, persepsi, dan pembelajaran. Oleh sebab itu, kecemasan dapat menghambat fungsi kognitif yang berpengaruh pada performa ketika ujian. Kecemasan yang timbul ketika menghadapi ujian akan mempengaruhi performa mahasiswa yaitu mereka dengan tingkat kecemasan yang lebih rendah performanya akan lebih baik dibanding mereka yang mengalami kecemasan sedang dan tinggi (Nilifda et al, 2016). Penelitian sebelumnya menyebutkan bahwa responden yang tidak 
mengalami kecemasan cenderung memiliki kualitas tidur baik sebanyak 11 orang $(20,8 \%)$, responden yang mengalami kecemasan ringan cenderung memiliki kualitas tidur buruk sebanyak 15 orang $(28,1 \%)$ sedangkan responden mengalami kecemasan sedang seluruhnya memiliki kualitas buruk sebanyak 9 responden $(17,0 \%)$ (Hastuti et al, 2016).

Berdasarkan latar belakang dan pengalaman peneliti sebagai mahasiswa fakultas kedokteran, sebagian besar didapati beberapa dari mahasiswa kedokteran mengalami peningkatan kecemasan saat menghadapi ujian dikarenakan kualitas tidur yang menurun. Hal ini dapat pula terjadi pada mahasiswa baru dikarenakan perlunya adaptasi yang dilakukan sehingga membuat mahasiswa baru fakultas kedokteran Universitas Malahayati tahun 2019 belum terbiasa dengan lingkungan kamar dimana terdapat 4 orang dalam satu kamar di Asrama Universitas Malahayati. Maka dari itu peneliti ingin mengetahui apakah ada atau tidak hubungan kualitas tidur dengan tingkat kecemasan mahasiswa dalam menghadapi ujian CBT pada mahasiswa baru di fakultas kedokteran Universitas Malahayati tahun 2019.

\section{METODE}

Penelitian ini adalah analitik dengan menggunakan Desain penelitian Cross Sectional, populasi adalah Mahasiswa baru fakultas kedokteran umum Universitas Malahayati tahun 2019 yang berjumlah 143 orang. Penarikan sampel menggunakan purposive sampling dengan berdasarkan perhitungan rumus slovin menghasilkan jumlah sampel 106 orang. Analisa data yang dilakukan adalah univariat dan bivariat dengan uji korelasi pearson.

\section{HASIL}

Analisis univariat dalam penelitian ini untuk mengetahui distribusi frekuensi usia, distribusi frekuensi jenis kelamin, distribusi frekuensi kualitas tidur, dan distribusi frekuensi kecemasan pada mahasiswa baru di fakultas kedokteran umum Universitas Malahayati tahun 2019. Sedangkan analisis bivariat dalam penelitian ini untuk mengetahui hubungan kualitas tidur dengan tingkat kecemasan mahasiswa dalam menghadapi ujian CBT pada mahasiswa baru di fakultas kedokteran umum Universitas Malahayati tahun 2019. Responden dalam penelitian ini berjumlah 106 orang. Hasil penelitian dari 106 responden didapat :

\section{Karakteristik Responden \\ Tabel 1. Distribusi frekuensi karakteristik responden berdasarkan umur mahasiswa baru.}

\begin{tabular}{ccc}
\hline Umur & Frekuensi & $\%$ \\
\hline $\mathbf{1 6}$ tahun & 1 & $9 \%$ \\
$\mathbf{1 7}$ tahun & 15 & $14.2 \%$ \\
$\mathbf{1 8}$ tahun & 55 & $51.9 \%$ \\
$\mathbf{1 9}$ tahun & 24 & $22.6 \%$ \\
$\mathbf{2 0}$ tahun & 8 & $7.5 \%$ \\
$\mathbf{2 1}$ tahun & 2 & $1.9 \%$ \\
$\mathbf{2 3}$ tahun & 1 & $9 \%$ \\
\hline Total & $\mathbf{1 0 6}$ & $\mathbf{1 0 0} \%$ \\
\hline
\end{tabular}

Berdasarkan tabel 1 di atas dapat dilihat bahwa dari 56 subjek penelitian berdasarkanumur, di dapatkan umur dengan kategori tidak beresiko (<45th)sebanyak 7 responden $(12,5 \%)$, lebih sedikit dibanding umur dengan kategori beresiko ( $\geq 45$ th) sebanyak 49 responden $(87,5 \%)$, dan untuk subjek penelitian berdasarkan jenis kelamin sebagian besar berjenis kelamin perempuan berjumlah 32responden (57,1 \%), sedangkan sisanya berjenis kelamin laki-laki berjumlah 24 responden (42,9\%). Berdasarkan tabel 1 diketahui dari 106 responden yang diteliti, didapatkan bahwa rata-rata mahasiswa berumur 18 tahun, yaitu 55 orang $(51,9 \%)$ mahasiswa dengan usia termuda 16 tahun sebanyak 1 orang ( $9 \%)$ serta mahasiswa dengan umur tertua 23 tahun sebanyak 1 orang ( $9 \%)$. 
Tabel 2. Distribusi frekuensi karakteristik responden berdasarkan jenis kelamin mahasiswa baru.

\begin{tabular}{ccc}
\hline Jenis Kelamin & Frekuensi & \% \\
\hline Laki-laki & 48 & $45.3 \%$ \\
Perempuan & 58 & $54.7 \%$ \\
\hline Total & $\mathbf{1 0 6}$ & $\mathbf{1 0 0 \%}$
\end{tabular}

Berdasarkan tabel 2 diketahui dari 106 responden yang diteliti, terlihat bahwa sebagian besar subjek penelitian adalah perempuan sebanyak 58 orang atau sekitar 54,7\% sedangkan laki-laki sebanyak 48 orang atau sekitar $45,3 \%$. Hal ini dapat terjadi karena dalam satu angkatan sebagian besar berjenis kelamin perempuan.

\section{Analisis Univariat}

1. Distribusi Frekuensi Kualitas Tidur

Tabel 3. Distribusi frekuensi kualitas tidur mahasiswa baru.

\begin{tabular}{ccc}
\hline Kualitas Tidur & Frekuensi & $\mathbf{\%}$ \\
\hline Baik & 30 & $28,3 \%$ \\
Buruk & 76 & $71,7 \%$ \\
\hline Total & $\mathbf{1 0 6}$ & $\mathbf{1 0 0 \%}$ \\
\hline
\end{tabular}

Berdasarkan tabel 3 diketahui dari 106 responden yang diteliti, terlihat bahwasebagian besar mahasiswa memiliki kualitas tidur buruk sebanyak 76 orang $(71,7 \%)$, sedangkan mahasiswa yang memiliki kualitas tidur baik sebanyak 30 orang $(28,3 \%)$.

\section{Distribusi Frekuensi Kecemasan}

Berdasarkan tabel 5 diketahui dari 106 responden yang diteliti, terlihat bahwasebagian besar mahasiswa mengalami kecemasan ringan sebanyak 46 orang $(43,4 \%)$, mahasiswa yang tidak ada kecemasan sebanyak 28 orang $(26,4 \%)$, mahasiswa yang memiliki kecemasan sedang sebanyak 26 orang $(24,5 \%)$ dan mahasiswa yang memiliki kecemasan berat sebanyak 6 orang $(5,7 \%)$.

Tabel 5. Distribusi frekuensi kecemasan mahasiswa baru.

\begin{tabular}{ccc}
\hline Kecemasan & Frekuensi & \% \\
\hline Tidak Ada & 28 & $26.4 \%$ \\
Ringan & 46 & $43.4 \%$ \\
Sedang & 26 & $24.5 \%$ \\
Berat & 6 & $5.7 \%$ \\
\hline Total & $\mathbf{1 0 6}$ & $\mathbf{1 0 0 \%}$ \\
\hline
\end{tabular}

Analisis Bivariat

Tabel 6. Hubungan kualitas tidur dengan tingkat kecemasan mahasiswa dalam menghadapi ujian cbt pada mahasiswa baru.

\begin{tabular}{ccccc}
\hline Variabel & Median & $\begin{array}{c}\text { (Min- } \\
\text { Max) }\end{array}$ & $\begin{array}{c}\boldsymbol{P}- \\
\text { value }\end{array}$ & Nilai r \\
\hline $\begin{array}{c}\text { Kualitas } \\
\text { Tidur }\end{array}$ & 7 & $2-19$ & & \\
Kecemasan & 16 & $5-35$ & & -0.2033 \\
\hline
\end{tabular}

Dari hasil uji normalitas data telah terdistribusi normal, maka uji statistik yang digunakan adalah uji korelasi pearson dengan nilai $a=0,05$ yang berarti apabila nilai $p<0,05$ maka terdapat hubungan yang bermakna antar kedua variabel $\left(\mathrm{H}_{0}\right.$ ditolak) dan apabila nilai $\mathrm{p}>0,05$ maka tidak terdapat hubungan yang bermakna ( $\mathrm{H}_{0}$ diterima). Berdasarkan hasil uji bivariat diatas, maka diperoleh nilai korelasi antara kualitas tidur dengan kecemasan sebesar -0,207, sesuai dengan pedoman interpretasi koefisien korelasi maka angka korelasi tersebut masuk dalam kategori hubungan rendah sehingga dapat dikatakan bahwa hubungan antara kualitas tidur dengan kecemasan mempunyai tingkat hubungan yang rendah dan tidak searah atau berlawanan, artinya apabila skor kualitas tidur tinggi maka skor tingkat kecemasan akan rendah begitu pula sebaliknya, apabila skor kualitas tidur 
rendah maka skor tingkat kecemasan akan tinggi.

\section{PEMBAHASAN \\ Univariat}

1. Distribusi frekuensi kualitas tidur mahasiswa baru.

Berdasarkan tabel 3 diketahui dari 106 responden yang diteliti, terlihat bahwasebagian besar mahasiswa memiliki kualitas tidur buruk sebanyak 76 orang $(71,7 \%)$, sedangkan mahasiswa yang memiliki kualitas tidur baik sebanyak 30 orang $(28,3 \%)$. Hasil ini didukung oleh Nilifda (2016), tentang "Hubungan Kualitas Tidur dengan Prestasi Akademik Mahasiswa Program Studi Pendidikan Dokter Angkatan 2010 FK Universitas Andalas" yang telah dilakukan terhadap 177 responden, didapatkan hasil bahwa sebanyak 78 orang (44\%) memiliki kualitas tidur yang baik dan 99 orang (53\%) memiliki kualitas tidur yang buruk.

Kualitas tidur yang buruk pada responden dikarenakan adanya faktor diri sendiri dimana pada penelitian ini mahasiswa baru fakultas kedokteran umum Universitas Malahayati masih beradaptasi dalam belajar ujian sehingga tidak dapat mengontrol kualitas tidur sendiri. Kualitas tidur merupakan suatu keadaan tidur yang dijalani seorang individu menghasilkan kesegaran dan kebugaran saat terbangun.Kualitas tidur mencakup aspek kuantitatif dan kualitatif tidur, seperti durasi tidur, latensi tidur, serta aspek subjektif dari tidur (Hastuti, 2016).

Kualitas tidur yang buruk dapat ditandai dengan tanda fisik dan psikologis, seperti ekspresi wajah (area gelap disekitar mata, bengkak di kelopak mata, konjungtiva kemerahan dan mata terlihat cekung), kantuk yang berlebihan (sering menguap), tidak mampu untuk berkonsentrasi (kurang perhatian), terlihat tandatanda keletihan seperti penglihatan kabur, mual dan pusing (Hidayat, 2013).

Kualitas tidur merupakan faktor penting untuk kesehatan. Ada bukti bahwa kurang tidur dapat menyebabkan lebih banyak kecelakaan. Kualitas tidur yang buruk memiliki dampak besar pada kesehatan fisik di jangka panjang. Sebuah peningkatan yang signifikan dari risiko penyakit jantung bahkan mungkin kematian. Selanjutnya, kualitas tidur sering dibahas dalam konteks dengan kesehatan mental. Bukti yang mendukung hipotesis bahwa kualitas tidur yang buruk berhubungan dengan kesehatan mental dan kesejahteraan menurun (Potter dan Perry, 2005).

\section{Distribusi frekuensi kecemasan mahasiswa baru di fakultas.}

Berdasarkan tabel 4 diketahui dari 106 responden yang diteliti, terlihat bahwasebagian besar mahasiswa mengalami kecemasan ringan sebanyak 46 orang $(43,4 \%)$, mahasiswa yang tidak ada kecemasan sebanyak 28 orang $(26,4 \%)$, mahasiswa yang memiliki kecemasan sedang sebanyak 26 orang $(24,5 \%)$ dan mahasiswa yang memiliki kecemasan berat sebanyak 6 orang $(5,7 \%)$. Hal ini didukung penelitian yang dilakukan oleh Hastuti (2016), tentang "hubungan tingkat kecemasan dengan kualitas tidur pada mahasiswa yang menyusun skripsi di Stikes Muhammadiyah Klaten" yang menghasilkan bahwa sebagian besar responden mengalami cemas ringan sebanyak 25 orang $(47,2 \%)$.

Kecemasan merupakan sinyal yang menyadarkan, memperingatkan suatu bahaya, ancaman cedera tubuh, rasa takut, keputusasaan, kemungkinan hukuman, frustasi dari kebutuhan sosial atau tubuh, dan perpisahan dari orang yang dicintai sehingga mengakibatkan munculnya tindakan oleh individu untuk mengatasi suatu ancaman (Kaplan et al, 2010).

Kecemasan pada mahasiswa sendiri dikarenakan ketidakteraturan jadwal istirahat dan bekerja, cemas dalam menghadapi ujian, stres. Kondisi tersebut dapat menjadi stressor timbulnya kecemasan yang disebabkan 
oleh teori psikologi dan teori biologi kecemasan (Ratnaningtyas, 2020).

\section{Bivariat}

Berdasarkan tabel 5 dapat dilihat bahwa $r=-0,207$ dengan $p$-value $=$ 0,033 yang berarti hubungan antara kualitas tidur dengan kecemasan memiliki korelasi yang negatif namun rendah dengan perbedaan yang signifikan. Hal ini berarti, apabila skor kualitas tidur tinggi maka skor tingkat kecemasan akan rendah begitupula sebaliknya, apabila skor kualitas tidur rendah maka skor tingkat kecemasan akan tinggi. Artinya pada mahasiswa baru fakultas kedokteran umum, mereka mengorbankan kualitas tidur mereka menjadi buruk untuk belajar demi menghadapi ujian CBT, sehingga mereka merasa puas dengan hasil belajar dan menghasilkan tingkat kecemasan yang rendah.

Hasil penelitian ini sejalan denganRatnaningtyas (2020), didapatkan hasil uji statistik juga menunjukkan $P$ Value sebesar 0,014 dimana nilai tersebut kurang dari $a=$ 0,05. Hal tersebut menunjukkan terdapat hubungan yang bermakna antara kecemasan dengan kualitas tidur pada mahasiswa tingkat akhir.

Data lain mengungkapkan bahwa hasil uji statistik diperoleh nilai $\mathrm{p}=$ $0,000 \quad(p<0,05)$ maka disimpulkan adanya hubungan antara kualitas tidur dengan tingkat kecemasan. Dari hasil analisis diperoleh $\mathrm{OR}=0,094$ artinya responden yang memiliki kualitas tidur buruk mempunyai peluang 0,094 kali untuk mengalami kecemasan ringan dibandingkan responden yang memiliki kualitas tidur baik (Demur, 2018).

Kecemasan mahasiswa dapat dipengaruhi dari banyak faktor, salah satunya adalah kualitas tidur. Kondisi yang menyebabkan gangguan tidur pada mahasiswa adalah kondisi lingkungan kamar, sehingga kondisi ini dapat mempengaruhi kualitas tidur (Setyawan, 2017). Kecemasan dalam penelitian ini dipengaruhi faktor yang bersumber dari individu (faktor internal). Faktor yang bersumber dari individu adalah faktor biologis (genetik), kondisi tubuh (penyakit), dan tingkah laku. Faktor kondisi tubuh yaitu penyakit kronis atau cacat tubuh. Faktor tingkah laku, yaitu gaya hidup (Kaplan et al, 1997).

Kualitas tidur adalah kepuasan seseorang tentang pengalaman tidur, mengintegrasikan aspek inisiasi tidur, pemeliharaan tidur, kuantitas/lamanya tidur, dan penyegaran saat bangun. Kualitas tidur sering dibahas dalam konteks dengan kesehatan mental. Bukti yang mendukung hipotesis bahwa kualitas tidur yang buruk berhubungan dengan kesehatan mental dan kesejahteraan menurun (Kaplan et al, 2010). Beberapa faktor yang mempengaruhi kualitas tidur yaitu, faktor fisiologis, faktor psikologis, lingkungan dan gaya hidup. Dari faktor fisiologis berdampak dengan penurunan aktivitas sehari - hari, rasa lemah, lelah, daya tahan tubuh menurun, dan ketidakstabilan tanda tanda vital, sedangkan dari faktor psikologis berdampak depresi, cemas, dan sulit untuk konsentrasi (Potter dan Perry, 2005).

Sampai saat ini belum ada peneliti yang menjelaskan hubungan antara kualitas tidur dengan tingkat kecemasan. Namun dipercayai dikarenakan kondisi kualitas tidur yang buruk, mahasiswa dapat mengalami perubahan emosi meliputi kecemasan.

\section{KESIMPULAN}

Berdasarkan hasil penelitian mengenai hubungan kualitas tidur dengan tingkat kecemasan mahasiswa dalam menghadapi ujian CBT pada mahasiswa baru di fakultas kedokteran umum Universitas Malahayati tahun 2019, diperoleh kesimpulan sebagai berikut:

1. Diketahui distribusi frekuensi kualitas tidur mahasiswa baru fakultas kedokteran umum Universitas Malahayati terlihat bahwasebagian besar mahasiswa memiliki kualitas tidur buruk sebanyak 76 orang $(71,7 \%)$.

2. Diketahui distribusi frekuensi kecemasan mahasiswa baru 
fakultas kedokteran umum Universitas Malahayati terlihat bahwa mahasiswa yang tidak ada kecemasan sebanyak 28 orang $(26,4 \%)$.

3. Diketahui ada hubungan kualitas tidur dengan tingkat kecemasan mahasiswa dalam menghadapi ujian CBT pada mahasiswa baru di fakultas kedokteran umum Universitas Malahayati tahun 2019 dengan nilai $p$-value $=0,033$, $r=-0,207$.

\section{SARAN}

Saran yang dapat peneliti sampaikan pada penelitian ini adalah:

1. Bagi mahasiswa

Menyarankan kepada mahasiswa agar lebih memperhatikan kualitas tidur dengan mengatur waktu belajar dari jauh hari sebelum menghadapi ujian agar mendapatkan hasil yang baik.

2. Bagi institusi

Menyarankan kepada fakultas untuk memberikan materi tentang kestabilan emosi. Sehingga diharapkan mahasiswa dapat mengontrolagar tidak mengalami kondisi kecemasan terutama dalam menghadapi ujian agar menunjang mahasiswa untuk mendapatkan nilai ujian yang baik.

3. Bagi peneliti selanjutnya

Menyarankan agar peneliti selanjutnya untuk melakukan penelitian lebih lanjut mengenai faktor yang dapat mempengaruhi kualitas tidur. Untuk peneliti selanjutnya diharapkan untuk lebih mendampingi dan mengawasi responden saat pengisian kuesioner untuk mengurangi kesulitan responden saat pengisian sehingga dengan harapan mendapatkan hasil yang lebih baik.

\section{DAFTAR PUSTAKA}

Amir, D. P., Iryani, D., \& Isrona, L. (2016). Hubungan Tingkat Kecemasan dalam Menghadapi Objective Structured Clinical Examination (OSCE) dengan Kelulusan OSCE pada Mahasiswa
Fakultas Kedokteran Universitas Andalas. Jurnal Kesehatan Andalas 5(1):139-144.

Demur, D. R. D. N. (2018). Hubungan Kualitas Tidur dengan Tingkat Kecemasan pada Pasien Terpasang Infus di Ruang Rawat Inap Interne RSUD Dr. Achmad Mochtar Bukit tinggi. Jurnal Kesehatan Perintis (Perintis's Health Journal) 5(2):150-155.

Hastuti, R. Y., Sukandar, A., \& Nurhayati, T. (2016). Hubungan Tingkat Kecemasan dengan Kualitas Tidur pada Mahasiswa yang Menyusun Skripsi di STIKES Muhammadiyah Klaten. MOTORIK Jurnal IImu Kesehatan 11(22):921.

Hidayat Aa, (2009). Kebutuhan Dasar Manusia. Jakarta: Salemba Medika

Kaplan H.I, Sadock B.J, Grebb J.A. (1997). Sinopsis Psikiatri Jilid 1. Edisi Ke-7. Terjemahan Widjaja Kusuma. Jakarta: Binarupa Aksara.

Kaplan H.I, Sadock B.J, Grebb J.A. (2010). Sinopsis Psikiatri Jilid 2. Terjemahan Widjaja Kusuma. Jakarta: Binarupa Aksara. P.

Kesuma, S.K., Rozalina, \&Zakiah, M., (2017). Gambaran Tingkat Kecemasan Mahasiswa Kedokteran Yang Mengikuti Uji Kompetensi Mahasiswa Program Profesi Dokter Di Fakultas Kedokteran Universitas Tanjungpura Tahun 2017. Jurnal Mahasiswa PSPD FK Universitas Tanjungpura 3(2) : .

Nilifda, H., Nadjmir, N. \& Hardisman, H., (2016). Hubungan Kualitas Tidur Dengan Prestasi Akademik Mahasiswa Program Studi Pendidikan Dokter Angkatan 2010 FK Universitas Andalas. Jurnal Kesehatan Andalas 5(1):243-249.

Potter Pa, Perry Ag, (2010). Fundamental Keperawatan. Edisi 7. Fitriani Dn, Trans. Jakarta: Salemba Medika.

Ratnaningtyas, T. O., \& Fitriani, D. (2020). Hubungan Kecemasan dengan Kualitas Tidur Pada 
Mahasiswa Tingkat Akhir. Edu

Masda Journal 4(1), 21-31.

Setyawan, A.B., (2017). Hubungan

Tingkat Kecemasan Dengan

Kualitas Tidur Pasien Pre Operasi

Di Ruang Angsoka Rumah Sakit

Abdul Wahab Sjahranie

Samarinda. Jurnal IImiah Sehat

Bebaya 1(2):110-116. 